\title{
Long-term Outcomes of Endoscopic Papillary Large-balloon Dilation for Common Bile Duct Stones
}

\author{
Toji Murabayashi, Yoshihide Kanno, Shinsuke Koshita, Takahisa Ogawa, Hiroaki Kusunose, \\ Toshitaka Sakai, Kaori Masu, Keisuke Yonamine, Kazuaki Miyamoto, Fumisato Kozakai, \\ Kazuki Endo, Yutaka Noda and Kei Ito
}

\begin{abstract}
:
Objective Endoscopic papillary large-balloon dilation (EPLBD) for common bile duct (CBD) stone removal has been confirmed to be safe and effective in the short term. The long-term outcomes of EPLBD, which have not been sufficiently evaluated, were therefore investigated in this study.

Methods For patients who had undergone endoscopic CBD stone removal with EPLBD between October 2011 and December 2015, follow-up surveys were conducted using a postal survey, telephone interview, or medical record review in August 2017. The main outcome measurement was the recurrence rate of CBD stones after complete stone removal with EPLBD in patients who received follow-up for more than one year. Risk factors for such recurrence were secondarily analyzed.

Results Of the 98 patients treated using EPLBD, 93 (95\%) were followed up after complete stone removal and analyzed for the long-term outcomes. During the mean follow-up period of $33.7 \pm 16.6$ months, CBD stones recurred in 16 patients (17\%) with a mean interval of $12.7 \pm 12.7$ months. Univariate analyses showed that a large stone size, multiple stones, a large distal CBD diameter, and a history of cholecystectomy were significant risk factors for stone recurrence $(\mathrm{p}=0.022,0.013,0.001$ and 0.035 , respectively). The large distal CBD diameter was the only significant risk factor for stone recurrence in a multivariate analysis (hazard ratio, $1.227 ; \mathrm{p}=0.031$ ).

Conclusion The long-term outcomes of EPLBD for CBD stones, including the rate of stone recurrence, were found to be acceptable. A large distal CBD diameter was an independent risk factor for stone recurrence.
\end{abstract}

Key words: endoscopic papillary balloon dilation, endoscopic retrograde cholangiopancreatography, difficult stone, recurrence

(Intern Med 59: 891-899, 2020)

(DOI: 10.2169/internalmedicine.3881-19)

\section{Introduction}

Endoscopic sphincterotomy (EST) is a well-established, standard technique for preparing to remove common bile duct (CBD) stones. However, endoscopic removal is often challenging for difficult stones, such as huge stones, numerous stones, or stones in the tortuous bile duct, even if EST is successfully performed. Ersoz et al. first reported using endoscopic papillary large-balloon dilation (EPLBD) follow- ing EST to remove such difficult CBD stones in 2003 (1). Since then, EPLBD has been confirmed to be safe and effective with respect to the short-term outcomes (2-5).

According to several meta-analyses, the rates of early adverse events and mechanical lithotripsy usage are significantly lower when large or multiple stones have been removed after EPLBD than when EPLBD is not performed (2-4). However, the long-term outcomes of EPLBD have not been sufficiently evaluated (6-15). An impaired function of the biliary sphincter due to EPLBD might in- 
duce complications derived from reflux (16), whereas a widely opened orifice might prevent new stone formation.

Therefore, we conducted this retrospective cohort study to evaluate the long-term outcomes of EPLBD for CBD stones, including the rate of stone recurrence and its risk factors.

\section{Materials and Methods}

\section{Patients}

All patients who underwent EPLBD for CBD stone removal at our center between October 2011 and December 2015 were extracted using a prospectively maintained database. EPLBD was defined as mechanical dilation of the major duodenal papilla using a balloon with a diameter $\geq 12$ $\mathrm{mm}$. When stones were large (maximal diameter $\geq 10 \mathrm{~mm}$ ) or multiple $(\geq 3)$ in the dilated $(\geq 10 \mathrm{~mm})$ distal bile duct, EPLBD was performed at the endoscopist's discretion. Patients with acute pancreatitis, coagulopathies (prothrombin time-international normalized ratio $\geq 1.6$ ), a platelet count $\leq$ $50,000 / \mu \mathrm{L}$, or antithrombotic therapy did not undergo EPLBD. Patients with a history of surgical choledochoduodenostomy or endoscopic papillectomy and those with biliary stricture were excluded from this study because such conditions might be disturbing factors that influence the long-term outcomes. The presence of CBD stones was confirmed using imaging examinations, including abdominal ultrasonography (US), computed tomography (CT), magnetic resonance imaging (MRI), and/or endoscopic ultrasound (EUS), before endoscopic stone removal.

This study was approved by the Institutional Review Board of our center (registration number: 2017-0020). All patients provided their written informed consent for the endoscopic procedures.

\section{Endoscopic procedures}

Endoscopic retrograde cholangiopancreatography (ERCP) was performed using a duodenoscope (TJF-260V, JF-260V; Olympus, Tokyo, Japan) under moderate sedation with intravenous administration of midazolam and pentazocine. For patients with a surgically altered anatomy, such as Billroth II and Roux-en-Y reconstruction, an oblique viewing endoscope (XK-240; Olympus) or a single-balloon enteroscope (SIF-Q260; Olympus) was used. After cholangiography was performed with a selectively inserted 5.5-Fr cannula (StarTip PR-104Q-1 or PR-110Q-1; Olympus), small or middle-sized EST was performed if it had not been previously performed. A balloon catheter (GIGA, Century Medical, Tokyo, Japan; CRE, Boston Scientific Japan, Tokyo, Japan; StoneMaster V, Olympus) was positioned across the papilla and gradually inflated under endoscopic and fluoroscopic guidance. The balloon was usually kept inflated for 30 seconds after the diameter reached the intended size that had been determined in reference to the size of the largest stone and the distal CBD. The balloon was not fully inflated to the intended size when the tapered distal bile duct was stiff and could not be expanded smoothly and when abdominal pain newly emerged. CBD stones were removed using a basket and/or a balloon catheter after EPLBD.

Huge stones were crushed using a mechanical lithotripter. Complete stone removal was confirmed by the absence of filling defects in the final cholangiography obtained using a balloon catheter. When stones were not completely removed during the EPLBD session, a plastic stent was temporarily placed to avoid biliary obstruction, and endoscopic procedures were repeated until complete removal was achieved. All patients were hospitalized for at least 24 hours after endoscopic treatment to evaluate adverse events, especially post-ERCP pancreatitis.

\section{Follow-up investigation}

Patients in whom stones were not completely removed were excluded from the evaluation of the long-term outcomes (Fig. 1). The prevalence of biliary complications during the follow-up period was finally evaluated on August 2017. In patients who were regularly followed up at the outpatient clinic after EPLBD, symptoms related to biliary complications (such as abdominal pain and jaundice) and blood examination and/or abdominal US findings were evaluated at every follow-up visit. When biliary complications were suspected, additional examinations, such as CT, EUS, and ERCP, were performed. For patients whose follow-up was terminated within a year after the procedure, postal and/or telephone surveys were conducted to evaluate biliary complications and the survival in August 2017 (Fig. 1). A postal questionnaire including the following three items was initially sent to all patients: 1) occurrence of biliary complications, including CBD stone recurrence, cholangitis, and cholecystitis, experienced at another hospital; 2) treatment for the complication (if applicable); and 3) the date and cause of death (if applicable). If there was no response to the questionnaire or the response was insufficient, a telephone interview with the patient or the primary care doctor was conducted by one of the investigators (T. M.). When on-going biliary complications were suspected based on their symptoms in these surveys, patients were recommended to visit the outpatient clinic for the diagnosis and treatment. Patients who refused to reply or who inappropriately replied were excluded from the analyses of the longterm outcomes (Fig. 1). Patients without a diagnosis of biliary complications at another hospital nor symptoms possibly related to biliary complications were defined as being free from biliary complications until surveillance after the procedure. The follow-up period was defined as the time from complete stone removal to the latest date among the final visit, postal survey reply, telephone interview, and death.

\section{Outcome measurements}

The main outcome measurement was the recurrence rate of CBD stones after complete stone removal with EPLBD during the follow-up period. Secondary outcome measurements were technical success, procedure-related adverse 


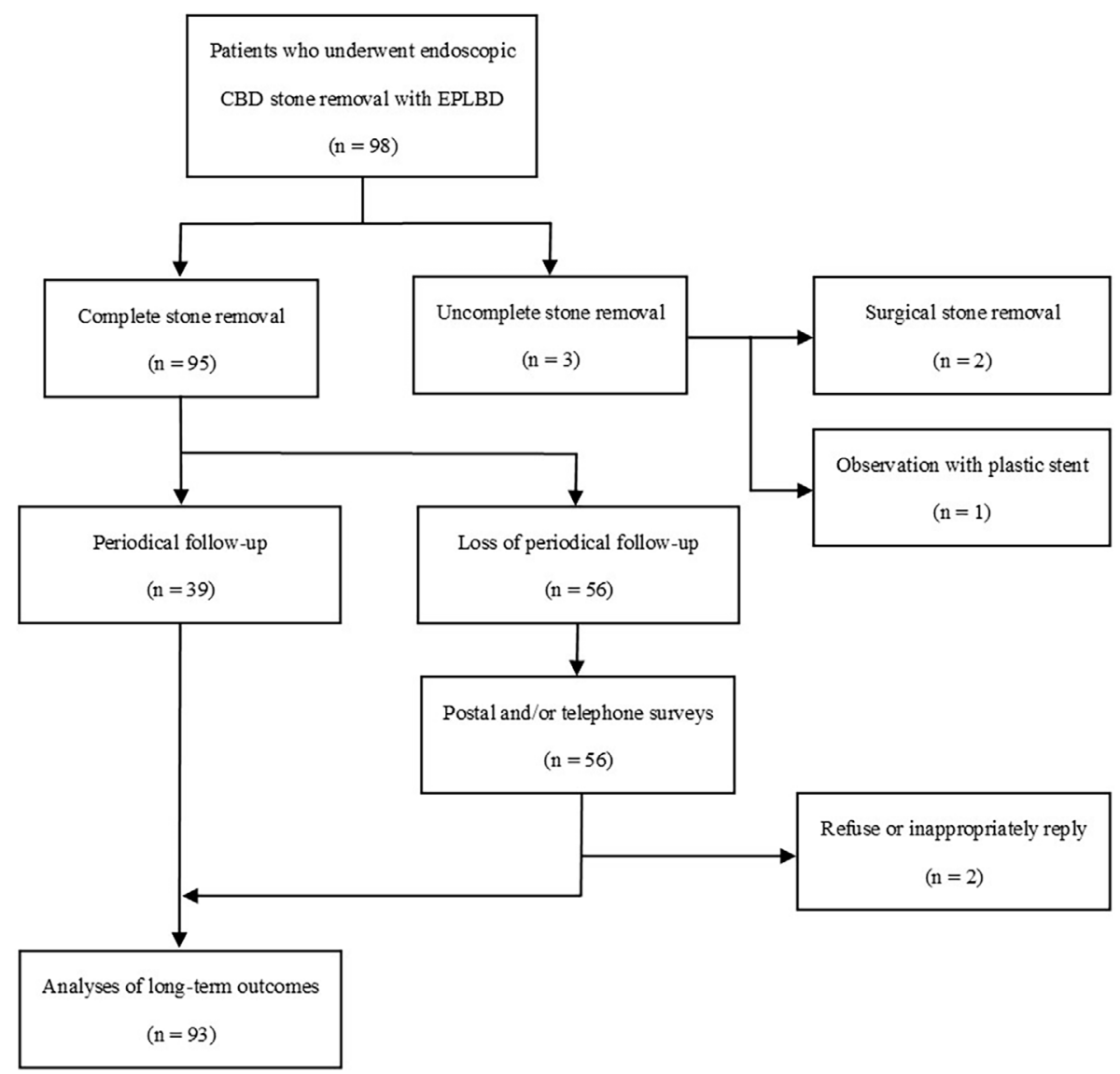

Figure 1. Flowchart of this study. CBD: common bile duct, EPLBD: endoscopic papillary largeballoon dilation

events, and the patient survival period. In addition, other biliary complications, such as acute cholecystitis, acute noncalculous cholangitis, liver abscess, and biliary cancer, during follow-up were evaluated. CBD stone recurrence was defined as recurrent stones confirmed by ERCP during the follow-up period.

In addition, risk factors for stone recurrence were analyzed. The following factors were investigated: the age, sex, the longest diameter of the largest stone, number of stones, diameter of the distal CBD, angle of the CBD curvature (7), tapered shape of the distal CBD, periampullary diverticulum, a history of CBD stone removal, surgically altered anatomy, a history of cholecystectomy, cholecystectomy within one month after EPLBD, gallbladder stones, number of ERCP sessions required for complete stone removal, total procedure time, and use of mechanical lithotripsy. The size of the balloon was not evaluated as a factor because of its correlation with the diameter of the distal CBD. The diameter and number of stones, diameter of the distal $\mathrm{CBD}$, tapered shape of the distal CBD, and angle of the CBD curvature were evaluated using endoscopic cholangiography. Sizes were measured in reference to the diameter of the endoscope. The total procedure time was defined as the total time of all endoscopic sessions required for complete stone removal. Procedure-related adverse events, such as post-ERCP pancreatitis (PEP), acute cholangitis, perforation, and bleeding, were defined according to the Consensus Criteria (17).

\section{Statistical analyses}

Continuous variables were presented as mean values with standard deviations, whereas categorical variables were reported as patient numbers and percentages. Continuous variables were compared using unpaired Student's $t$ - or MannWhitney tests, and categorical variables were compared using the chi-square or Fisher's exact tests, as appropriate. The cumulative recurrence rates of $\mathrm{CBD}$ stones during the follow-up period were analyzed using the Kaplan-Meier method. Univariate analyses using a log-rank test with Kaplan-Meier curves were performed for the abovementioned candidate factors. Factors with a $\mathrm{p}$ value $<0.1$ in the univariate analysis were extracted as candidates for the multivariate analysis using the Cox proportional hazard model. Hazard ratios and their 95\% confidence intervals were calculated from the results of the multivariate analysis. A p value of $<0.05$ was considered to be statistically significant. The SPSS software program (version 24; IBM Japan, Tokyo, Japan) was used for all analyses. 
Table 1. Patients' Characteristics.

\begin{tabular}{lc}
\hline Number of patients & 98 \\
Age, years & $78.8 \pm 8.7$ \\
Sex, male/female & $51 / 47$ \\
Largest stone size, mm & $16.1 \pm 5.2$ \\
Number of stones & $3.0 \pm 2.3$ \\
Diameter of the distal CBD, mm & $13.6 \pm 2.7$ \\
Angle of the CBD curvature, degrees & $139 \pm 21$ \\
Tapered shape of the distal CBD & $41(41.8 \%)$ \\
Periampullary diverticulum & $48(49.0 \%)$ \\
History of CBD stone removal & $42(42.9 \%)$ \\
Surgically altered anatomy & \\
$\quad$ None & $56(57.1 \%)$ \\
Distal gastrectomy, Billroth I reconstruction & $4(4.1 \%)$ \\
Distal gastrectomy, Billroth II reconstruction & $10(10.2 \%)$ \\
Distal gastrectomy, Roux-en Y reconstruction & $8(8.2 \%)$ \\
Total gastrectomy, Roux-en Y reconstruction & $20(20.4 \%)$ \\
Status of the gallbladder & \\
Previous cholecystectomy & $40(40.8 \%)$ \\
Gallbladder with stones in situ & $36(36.7 \%)$ \\
Gallbladder without stones in situ & $22(22.4 \%)$ \\
\hline
\end{tabular}

CBD: common bile duct
Table 2. Short-term Outcomes.

\begin{tabular}{lc}
\hline Balloon size, mm & $14.0 \pm 1.5$ \\
Complete stone removal & $95(96.9 \%)$ \\
Number of sessions required for complete stone removal & \\
1 & $78(82.1 \%)$ \\
$\geq 2$ & $17(17.9 \%)$ \\
Total procedure time, minutes & $62 \pm 45$ \\
Mechanical lithotripsy & $33(33.7 \%)$ \\
Adverse events & $6(6.1 \%)$ \\
Pancreatitis & 2 \\
Cholangitis & 1 \\
Cholecystitis & 1 \\
Bleeding & 1 \\
Perforation & 1 \\
\hline
\end{tabular}

telephone surveys after loss to follow-up. Ninety-three patients were ultimately analyzed for the long-term outcomes after the elimination of ineligible patients (Fig. 1).

During the mean follow-up period of 33.7 16.6 months, CBD stones recurred in 16 patients $(17.2 \%)$ with a mean interval of $12.7 \pm 12.7$ months (Fig. 2a). Recurrent stones (mean number of stones, 3.0 \pm 1.6 ; mean size of largest stone, $12.1 \pm 4.6 \mathrm{~mm}$ ) were removed using endoscopy in all cases. Acute cholangitis without stone recurrence, which was confirmed using ERCP, was observed for 3 patients (3.2\%). All of them improved with antibiotics.

Acute cholecystitis occurred in 5 of 48 patients (10.4\%) who had not undergone cholecystectomy. Of these five patients, four underwent cholecystectomy, and the other patient recovered with medication without intervention. Other biliary complications, such as liver abscess and biliary cancer, were not observed during the follow-up period.

Nineteen patients (20.4\%) died during follow-up for various reasons, including cardiac disease $(n=6)$, pneumonia $(n=$ 4), malignancy $(n=4)$, senility $(n=4)$, and traffic injury $(n=$ 1); no patients died of a biliary disease.

\section{Risk factors for CBD stone recurrence}

According to the univariate analyses using the log-rank test, a large stone size, multiple stones, a large CBD diameter, and history of cholecystectomy were significant risk factors for stone recurrence $(\mathrm{p}=0.022,0.013,0.001$, and 0.035 , respectively) (Table 3, Fig. 2b-e). Among the 6 factors with a $\mathrm{p}$ value $<0.1$, a large CBD diameter was the only significant risk factor for stone recurrence according to a multivariate analysis with the Cox proportional hazard model [hazard ratio, 1.227 (95\% confidence interval, 1.019-1.479), $\mathrm{p}=0.031]$ (Table 4).

\section{Discussion}

Since the confirmation of the technical safety and efficacy of EPLBD for removing large or multiple CBD stones, the long-term outcomes, including stone recurrence and other biliary events, have been discussed. After impairment of the

moval, 39 were periodically followed up at the outpatien clinic, and the other 56 were investigated using postal or 

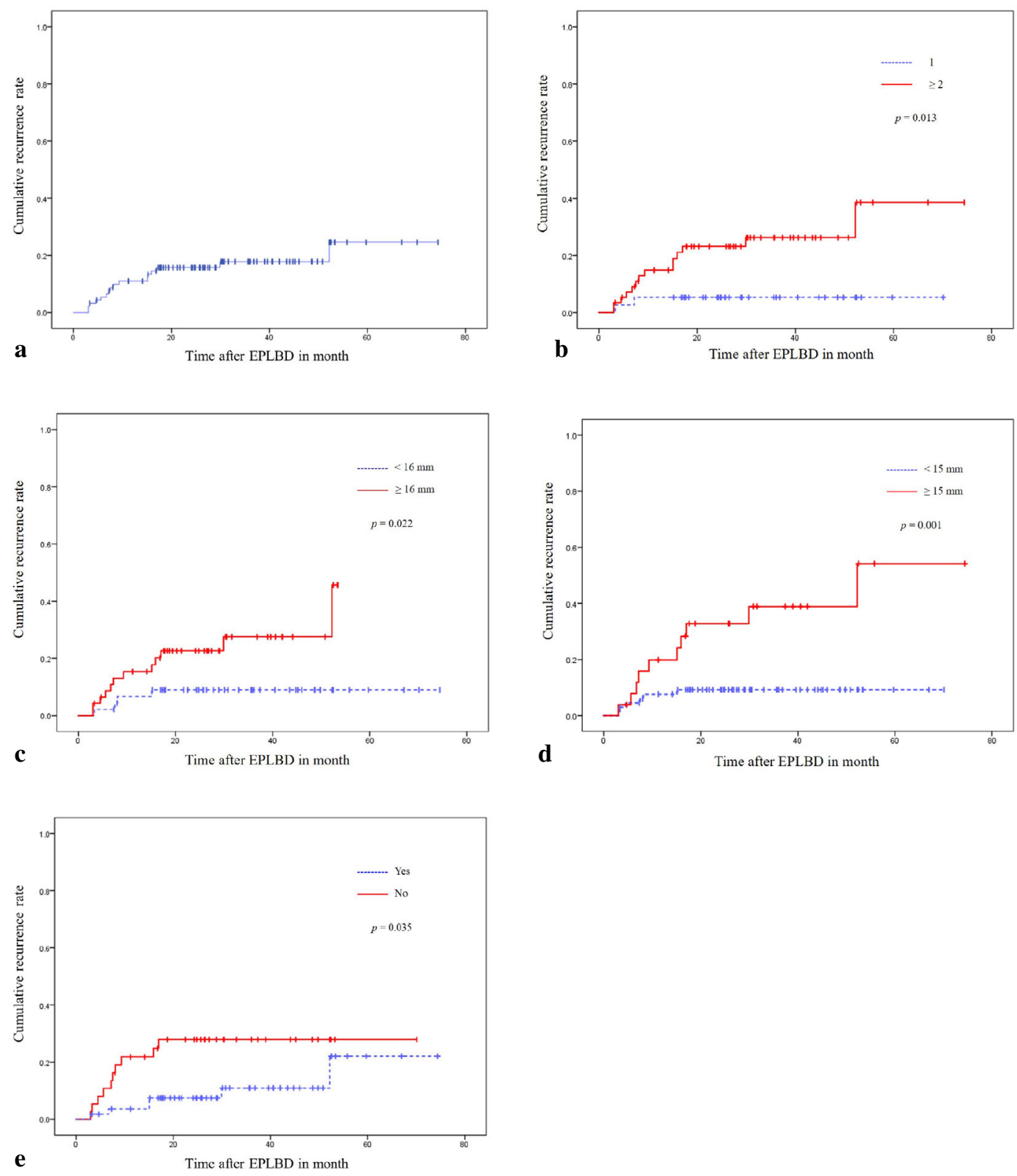

Figure 2. (a) Kaplan-Meier plot of the cumulative recurrence of CBD stones in a total of 93 patients after complete stone removal with EPLBD. CBD: common bile duct, EPLBD: endoscopic papillary large-balloon dilation (b) Kaplan-Meier plot of the cumulative recurrence of CBD stones divided by the number of stones. (c) Kaplan-Meier plot of the cumulative recurrence of CBD stones divided by the largest stone size. (d) Kaplan-Meier plot of the cumulative recurrence of CBD stones divided by the CBD diameter. (e) Kaplan-Meier plot of the cumulative recurrence of CBD stones divided by the history of cholecystectomy at EPLBD.

sphincter of Oddi function, stone formation can be induced by duodenobiliary reflux via the widely opened orifice, although this might paradoxically prevent stone formation as well because of a smooth bile flow. Nine studies focusing on the long-term outcomes of EPLBD have previously been reported (6-14) (Table 5). However, most of these studies are associated with methodological concerns, making a precise interpretation difficult.

Most patients did not undergo periodic follow-up after stone removal at the hospitals conducting the previous studies. The evaluation of the long-term complications seems to be less reliable because additional surveys, such as contact by phone or mail, were not conducted, resulting in a relatively high percentage of dropout candidates. We conducted such surveys under an elaborate study protocol to estimate the precise rates in order to minimize dropout (2 dropouts among 95 eligible patients). Although the cumulative stone recurrence rate was higher in the present study (17.2\%) than in those previous reports, our results appear to be more accurate. The insufficient evaluation of the long-term complications is reflected in the lack of a reported mortality rate in 7 of 9 studies $(6-9,11,13,14)$. We studied for the first time 
Table 3. Univariate Analyses of Risk Factors for Stone Recurrence Using the Log-rank Test.

\begin{tabular}{|c|c|c|c|}
\hline & $\mathrm{n}$ & recurrence, $n$ & $\mathrm{p}$ value \\
\hline Age, years & & & 0.734 \\
\hline$<80$ & 43 & 8 & \\
\hline$\geq 80$ & 50 & 8 & \\
\hline Sex & & & 0.442 \\
\hline Male & 46 & 7 & \\
\hline Female & 47 & 9 & \\
\hline Largest stone size, $\mathrm{mm}$ & & & 0.022 \\
\hline$<16$ & 46 & 4 & \\
\hline$\geq 16$ & 47 & 12 & \\
\hline Number of stones & & & 0.013 \\
\hline 1 & 37 & 2 & \\
\hline$\geq 2$ & 56 & 14 & \\
\hline Diameter of distal CBD, mm & & & 0.001 \\
\hline$<15$ & 67 & 6 & \\
\hline$\geq 15$ & 26 & 10 & \\
\hline Angle of the CBD curvature, degrees & & & 0.642 \\
\hline$<135$ & 33 & 5 & \\
\hline$\geq 135$ & 60 & 11 & \\
\hline Tapered shape of the distal CBD & & & 0.962 \\
\hline Yes & 40 & 7 & \\
\hline No & 53 & 9 & \\
\hline Periampullary diverticulum & & & 0.079 \\
\hline Present & 47 & 11 & \\
\hline Absent & 46 & 5 & \\
\hline History of CBD stone removal & & & 0.123 \\
\hline Yes & 39 & 10 & \\
\hline No & 54 & 6 & \\
\hline Surgically altered anatomy & & & 0.061 \\
\hline Billroth II or Roux-en Y reconstruction & 35 & 3 & \\
\hline None or Billroth I reconstruction & 58 & 13 & \\
\hline History of cholecystectomy & & & 0.035 \\
\hline Yes & 37 & 10 & \\
\hline No & 56 & 6 & \\
\hline Cholecystectomy within 1 month after EPLBD & & & 0.200 \\
\hline Yes & 45 & 10 & \\
\hline No & 48 & 6 & \\
\hline Gallbladder stones & & & 0.562 \\
\hline Yes & 34 & 5 & \\
\hline No & 59 & 11 & \\
\hline Number of sessions required for complete stone removal & & & 0.189 \\
\hline 1 & 76 & 11 & \\
\hline$\geq 2$ & 17 & 5 & \\
\hline Total procedure time, minutes & & & 0.889 \\
\hline$<60$ & 59 & 10 & \\
\hline$\geq 60$ & 34 & 6 & \\
\hline Mechanical lithotripsy & & & 0.163 \\
\hline Yes & 31 & 8 & \\
\hline No & 62 & 8 & \\
\hline
\end{tabular}

CBD: common bile duct, EPLBD: endoscopic papillary large-balloon dilation

the mortality by the cause of death in patients after EPLBD, noting that EPLBD appeared associated with relatively few critical events, even after a long interval.

In several previous studies, there were analytical problems in evaluating time-to-event outcomes. The rates and risks of late complications cannot be evaluated using simple divisions because they are strongly related to the elapsed time. To handle these time-related outcomes, statistical calculations for the cumulative survival, such as the log-rank test and Cox proportional hazard model, should be applied. 
Table 4. Multivariate Analysis of Risk Factors for Stone Recurrence Using the Cox Proportional Hazard Model.

\begin{tabular}{lccc}
\hline & HR & $95 \%$ CI & p value \\
\hline Largest stone size & 0.999 & $0.890-1.122$ & 0.886 \\
Number of stones & 1.039 & $0.842-1.283$ & 0.720 \\
Diameter of the distal CBD & 1.227 & $1.019-1.479$ & 0.031 \\
Periampullary diverticulum & 1.518 & $0.486-4.743$ & 0.473 \\
Billroth II or Roux-en Y reconstruction & 0.545 & $0.141-2.106$ & 0.379 \\
History of cholecystectomy & 2.316 & $0.821-6.531$ & 0.112 \\
\hline
\end{tabular}

HR: hazard ratio, $\mathrm{CI}$ : confidence interval, $\mathrm{CBD}$ : common bile duct

There has been only one study in which late complications and their risk factors were evaluated using appropriate statistical methods (13). In the study by Maruta et al. (13), the Cox proportional hazard model was applied to investigate risk factors for late adverse events-defined as stone recurrence, cholangitis, or cholecystitis after EPLBD or EST-and the results indicated that the number of endoscopic sessions required $(\geq 2)$ was the only significant risk factor. Other studies with assessments of long-term outcomes have instead applied the logistic regression model which is not suitable for investigating time-to-event risk factors because, for example, a patient without recurrence after five years and another without recurrence after only a year have the same significance in the logistic regression model. In the present study, the number of endoscopic sessions required was not a significant risk factor for stone recurrence according to a univariate analysis $(\mathrm{p}=0.189)$. The size and number of stones, which are theoretically associated with the number of endoscopic sessions, were found to have a larger impact than the number of sessions $(\mathrm{p}=0.022$ and 0.013 , respectively; Table 3).

In the present study, the large distal CBD diameter was the only significant risk factor for stone recurrence on the basis of the Cox proportional hazard model. Furthermore, it has been reported as a significant risk factor in several previous reports $(6,8,10,11)$. Although why stones tend to recur in the dilated CBD remains unclear, bile stasis and bacterial contamination due to hypofunction of the biliary outflow, which causes CBD dilation, may be involved. In addition, stone fragments may remain because of extreme difficulty in detecting small floating material in a large duct during the procedure. For such high-risk patients, periodic surveillance with the utmost care should be practiced in order the detect any stone recurrence.

We investigated acute cholangitis without stone recurrence separately from calculous cholangitis and found an occurrence rate of $3.2 \%$. Duodenobiliary reflux and bacterial contamination of the CBD due to impairment of the sphincter function after EPLBD may increase the risk of noncalculous cholangitis, which should be independently evaluated. In two of the three previous studies in which noncalculous cholangitis was analyzed $(8,12)$, no patients developed non-calculous cholangitis, and in the other study by $\mathrm{Li}$ et al. (10), the occurrence rate was $4.7 \%$ during a mean follow-up period of 71.6 months. EPLBD does not appear to be related to non-calculous cholangitis.

The occurrence rate of acute cholecystitis in patients without cholecystectomy was $10.4 \%$, which is similar to the rates reported in 3 previous studies $(4.8-10.7 \%)(8,10,14)$. In the present study, all 5 cases of acute cholecystitis occurred in patients with gallstones $(5 / 26,19.2 \%)$, whereas none of the other 22 patients without gallstones developed acute cholecystitis during the follow-up period $(0 / 22,0 \%)$. In a previous randomized trial (18), the authors recommended prophylactic cholecystectomy for patients with gallbladder stones after EST for CBD stone removal because of the high occurrence rate of recurrent biliary events, including acute cholecystitis, if cholecystectomy is not performed. In that randomized trial, $37 \%$ of patients (22/59) with gallstones who had been allocated to the wait-and-see group without cholecystectomy underwent cholecystectomy mainly for biliary pain $(n=13)$ or acute cholecystitis $(n=7)$ during a median follow-up period of 30 months. Based on the results of the present study, prophylactic cholecystectomy should also be recommended after EPLBD for patients with gallbladder stones. The present study also implied that EPLBD did not affect the development of acute cholecystitis in patients without gallstones.

Several limitations associated with the present study warrant mention. First, this was a single-center retrospective study with a relatively small population. However, all patients who underwent EPLBD for CBD stone removal during the study period were extracted using the prospectively maintained database in a high-volume center where $>2,000$ pancreatobiliary endoscopy procedures are performed per year. The prospective collection minimized selection bias, and abundant experience ensured clinical stability. Furthermore, well-designed, detailed and careful evaluations for long-term complications were conducted in this study, resulting in only two patients being excluded from the longterm analyses (Fig. 1). Second, since no control group was defined in this study, the results of EPLBD for CBD stone removal could not be compared with those of no EPLBD. A retrospective comparison was not considered to provide more valuable data than that of previously published comparative studies because EPLBD was applied at the endoscopist's discretion without any definite criteria and without detailed reasons described in the medical records during the 


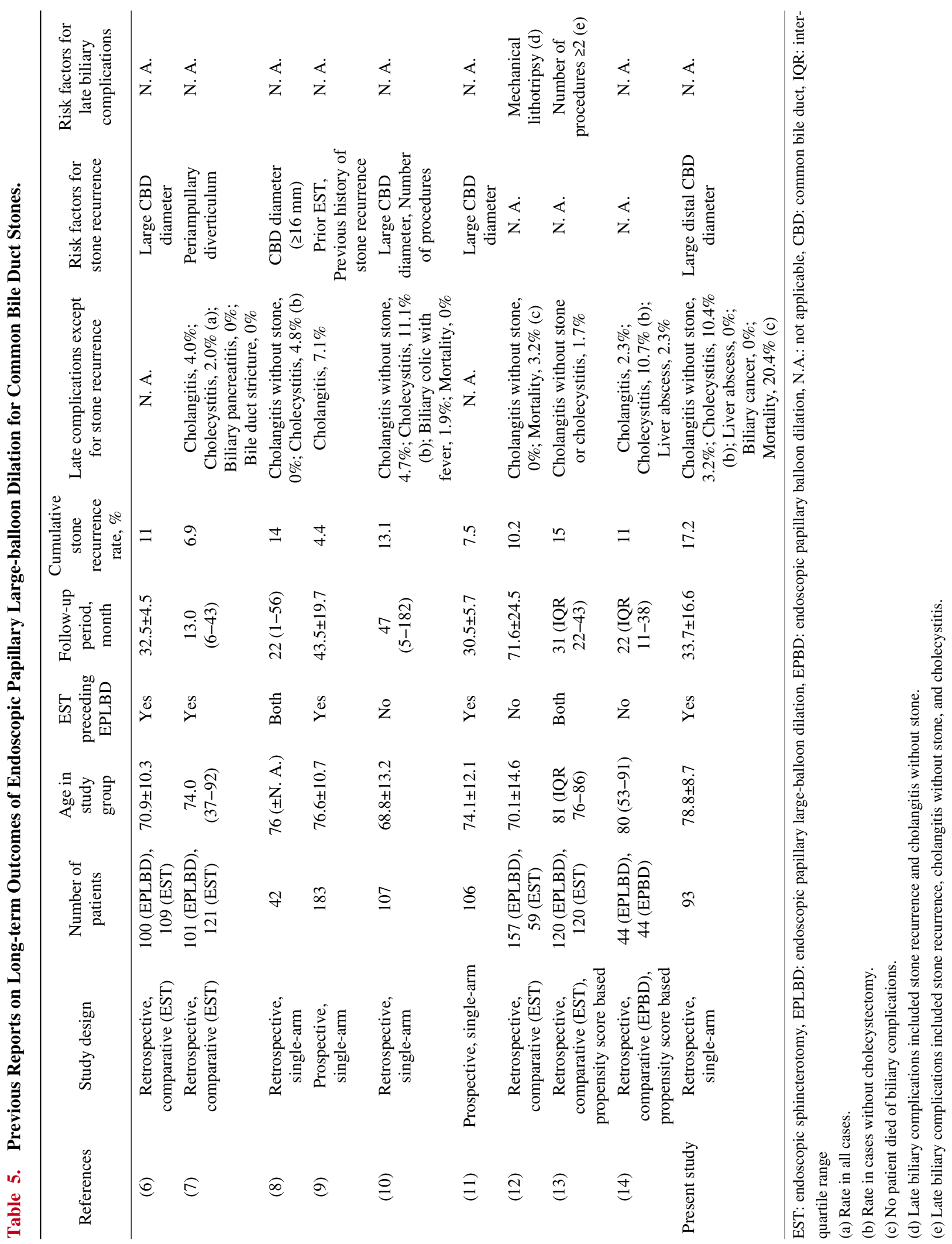

study period $(6,7,12-14)$. Finally, stones recurred after a relatively short interval in several cases in this study (Fig. 2a), suggesting that such recurrence might be attributed to not only newly formed stones but also residual stones. However, it is difficult to distinguish between true stone recurrence and residual stones. This means that the recurrence of CBD stones may include both types in real-world clinical practice.

In conclusion, the long-term outcomes of EPLBD for large or multiple CBD stones were found to be acceptable in this study with minimal dropouts from all retrospectively extracted patients; this means that the results were reliable 
as real-world data. A large distal CBD diameter was the only independent risk factor for stone recurrence. Further well-designed, prospective large-scale studies are warranted to establish strategies for removing difficult stones with the goal of improving the long-term outcomes.

The authors state that they have no Conflict of Interest (COI).

\section{References}

1. Ersoz G, Tekesin O, Ozutemiz AO, Gunsar F. Biliary sphincterotomy plus dilation with a large balloon for bile duct stones that are difficult to extract. Gastrointest Endosc 57: 156-159, 2003.

2. Feng Y, Zhu H, Chen X, et al. Comparison of endoscopic papillary large balloon dilation and endoscopic sphincterotomy for retrieval of choledocholithiasis: a meta-analysis of randomized controlled trials. J Gastroenterol 47: 655-663, 2012.

3. Kim JH, Yang MJ, Hwang JC, Yoo BM. Endoscopic papillary large balloon dilation for the removal of bile duct stones. World $\mathrm{J}$ Gastroenterol 19: 8580-8594, 2013.

4. Jin PP, Cheng JF, Liu D, Mei M, Xu ZQ, Sun LM. Endoscopic papillary large balloon dilation vs endoscopic sphincterotomy for retrieval of common bile duct stones: a meta-analysis. World J Gastroenterol 20: 5548-5556, 2014.

5. Xu L, Kyaw MH, Tse YK, Lau JY. Endoscopic sphincterotomy with large balloon dilation versus endoscopic sphincterotomy for bile duct stones: a systematic review and meta-analysis. Biomed Res Int 2015: 673103, 2015.

6. Kim KH, Rhu JH, Kim TN. Recurrence of bile duct stones after endoscopic papillary large balloon dilation combined with limited sphincterotomy: long-term follow-up study. Gut Liver 6: 107-112, 2012.

7. Kim KY, Han J, Kim HG, et al. Late Complications and stone recurrence rates after bile duct stone removal by endoscopic sphincterotomy and large balloon dilation are similar to those after endoscopic sphincterotomy alone. Clin Endosc 46: 637-642, 2013.

8. Kogure H, Tsujino T, Isayama $\mathrm{H}$, et al. Short- and long-term outcomes of endoscopic papillary large balloon dilation with or without sphincterotomy for removal of large bile duct stones. Scand J Gastroenterol 49: 121-128, 2014.
9. Itokawa F, Itoi T, Sofuni A, et al. Mid-term outcome of endoscopic sphincterotomy combined with large balloon dilation. J Gastroenterol Hepatol 30: 223-229, 2015.

10. Park JS, Jeong S, Bang BW, Kang AR, Lee DH. Endoscopic papillary large balloon dilatation without sphincterotomy for the treatment of large common bile duct stone: long-term outcomes at a single center. Dig Dis Sci 61: 3045-3053, 2016.

11. Paspatis GA, Paraskeva K, Vardas E, et al. Long-term recurrence of bile duct stones after endoscopic papillary large balloon dilation with sphincterotomy: 4-year extended follow-up of a randomized trial. Surg Endosc 31: 650-655, 2017.

12. Li T, Wen J, Bie L, Gong B. Comparison of the long-term outcomes of endoscopic papillary large balloon dilation alone versus endoscopic sphincterotomy for removal of bile duct stones. Gastroenterol Res Pract 2018: 6430701, 2018.

13. Maruta A, Iwashita $T$, Uemura $S$, et al. Comparison of late adverse events after endoscopic sphincterotomy versus endoscopic papillary large balloon dilation for common bile duct stones: a propensity score-based cohort analysis. Dig Endosc 30: 493-500, 2018.

14. Hakuta R, Kawahata $S$, Kogure $H$, et al. Endoscopic papillary large balloon dilation and endoscopic papillary balloon dilation both without sphincterotomy for removal of large bile duct stones: a propensity-matched analysis. Dig Endosc 31: 59-68, 2019.

15. Itoi T, Ryozawa $S$, Katanuma A, et al. Japan Gastroenterological Endoscopy Society guidelines for endoscopic papillary large balloon dilation. Dig Endosc 30: 293-309, 2018.

16. Cheon YK, Lee TY, Kim SN, Shim CS. Impact of endoscopic papillary large-balloon dilation on sphincter of Oddi function: a prospective randomized study. Gastrointest Endosc 85: 782-790, 2017.

17. Cotton PB, Eisen GM, Aabakken L, et al. A lexicon for endoscopic adverse events: report of an ASGE workshop. Gastrointest Endosc 71: 446-454, 2010.

18. Boerma D, Rauws EA, Keulemans YC, et al. Wait-and-see policy or laparoscopic cholecystectomy after endoscopic sphincterotomy for bile-duct stones: a randomised trial. Lancet 360: 761-765, 2002.

The Internal Medicine is an Open Access journal distributed under the Creative Commons Attribution-NonCommercial-NoDerivatives 4.0 International License. To view the details of this license, please visit (https://creativecommons.org/licenses/ by-nc-nd/4.0/).

(C) 2020 The Japanese Society of Internal Medicine Intern Med 59: 891-899, 2020 